\title{
COVID-19 in dermatology practice: getting back on track
}

\author{
Kathryn Anne G. Cembrano ${ }^{1}$ - Janice Natasha $\mathrm{Ng}^{1}$ • Yong Rongrungruang ${ }^{2}$ - Prasert Auewarakul ${ }^{3}$. \\ Mitchel P. Goldman ${ }^{4} \cdot$ Woraphong Manuskiatti $^{1}$
}

Received: 22 April 2020 / Accepted: 17 May 2020 / Published online: 23 June 2020

(C) Springer-Verlag London Ltd., part of Springer Nature 2020

The increasing number of confirmed COVID-19 cases emphasizes the importance of preventive measures among healthcare workers (HCWs) [1]. The field of dermatology is not exempt from this global issue. Although elective procedures are already suspended, some continued to perform lasers and energy-based device (EBD) treatments during the initial period of the pandemic. Others may not have been aware of the possibility of disease transmission while performing the said procedures. There is a high chance of contracting or even transmitting the disease to and from the patient because of the close distance maintained. Patients can be categorized into two groups: those with severe symptoms documented with a COVID-19 diagnosis and those with undocumented infections which is estimated to cause $86.2 \%$ of all cases [2].

Although coronaviruses are isolated from human epithelial cells of the upper or lower respiratory tract, viral shedding in plasma or serum is also common [3]. Therefore, there is a theoretical risk of transmission of coronaviruses through the blood products of infected individuals. As there is an increasing number of asymptomatic patients, dermatologists should be fully aware of the potential risk of transmission of severe acute respiratory syndrome coronavirus 2 (SARS-CoV-2) while performing laser and EBD procedures, and geared with complete biosafety protection.

Woraphong Manuskiatti

woraphong.man@mahiadol.edu

1 Department of Dermatology, Faculty of Medicine Siriraj Hospital, Mahidol University, 2 Wanglang Road, Bangkok 10700, Thailand

2 Division of Infectious Diseases and Tropical Medicine, Department of Medicine, Faculty of Medicine Siriraj Hospital, Mahidol University, Bangkok, Thailand

3 Department of Microbiology, Faculty of Medicine Siriraj Hospital, Mahidol University, Bangkok, Thailand

4 University of California, San Diego and Cosmetic Laser Dermatology: A West Dermatology Company, San Diego, CA, USA

\section{Preventive measures in dermatology practice}

The principal preventive initiatives for COVID-19 include administrative guidelines for patients and staff, correct usage of personal protective equipment (PPE), and engineering measures.

\section{Administrative measures for patients}

All non-emergency dermatology consults and procedures must be rescheduled. Screening patients and cancelling appointments only for those with fever is not enough because of the known viral shedding during asymptomatic or pre-symptomatic period [4]. Given the pandemic situation and asymptomatic shedding of SARS-CoV-2, offering universal face masks and alcohol-based handrubs (ABHRs) to all patients should be considered. Routine postoperative visits must likewise be suspended and advised teledermatology instead (Table 1).

\section{Administrative measures for staff}

Recommendations of administrative measures for staff are summarized in Table 2. Hand hygiene is considered the most critical measure in reducing the risk of transmission [5]. As previously mentioned, SARS-CoV-2 can be inactivated through protein denaturation by using ABHRs, given without visible soiling. If visible soiling is present, mechanical removal and disinfection by hand washing with antiseptic soap is preferred. The WHO recommends $80 \%$ ethanol $(\mathrm{v} / \mathrm{v})$ or $75 \%$ isopropanol ( $\mathrm{v} / \mathrm{v})$ as these were previously found to have virucidal action against SARS-CoV and Middle East Respiratory Syndrome coronavirus (MERS-CoV). The USCDC, on the other hand, maintains that the use of ABHR containing $60 \%$ ethanol or $70 \%$ isopropanol is sufficient. A combination of the "My 5 Moments for Hand Hygiene" protocol by the WHO as well as the use of the "Six-Step HandHygiene Technique" ensures adequate coverage of all hand skin surfaces at key moments in patient care. 
Table 1 Checklist of administrative measures for patients during the COVID-19 pandemic

Rescheduling all non-urgent appointments

\section{Cancelling appointments for patients who have the following:}

Low-grade fever $\left(\geq 37.3^{\circ} \mathrm{C}\right)^{*}$

Flu-like symptoms (cough, colds, shortness of breath)

Risks and exposures: recent travel history, contact with suspected or confirmed COVID-19 infected patients

\section{When patients arrive in the clinic}

Putting up posters on COVID-19 preventive measures for patient education

Temperature checks

Donning of universal face masks

Hand-cleaning with ABHR or soap and water

Limiting non-patient visitors

\section{Inside the clinic}

Placing chairs 3-6 feet apart and using barriers (like screens), if possible

Removing toys, reading materials, or other communal objects or disinfecting them regularly

\section{After patients leave the clinic}

Cleaning frequently touched surfaces (counters, beds, seats) using EPA*-registered disinfectants.

COVID-19, coronavirus disease 2019; EPA, Environmental Protection Agency; ABHR, alcohol-based handrub. Guided by the WHO. Getting your workplace ready for COVID-19. 2020; https://www.who.int/docs/default-source/coronaviruse/getting-workplace-ready-for-covid-19.pdf. Accessed 3 March 2020, 2020

\section{Personal protective equipment}

PPEs are the final line of protection for HCWs especially during the time of community transmission. For urgent procedures wherein laser and/or dermatologic surgeries are the primary treatment options, full protective gear must be worn and properly disposed of after. Goggles for eye protection are indicated at all times to prevent inoculation of the virus on the conjunctival surface.

The possibility of exposure to COVID-19 exists for operating personnel during procedures, especially with ablative lasers, lasers producing tissue spatter (Q-switched and picosecond lasers), and electrosurgery. According to the WHO, a healthy HCW needs to wear a face mask if he or she is taking care of a person with suspected COVID-19 infection. [6] However, mask-wearing during all patient contact points is suggested as HCWs may be unknowingly exposed to undocumented infected patients and asymptomatic carriers. Regarding source control, covering the mouth and nose of a patient with a facemask during laser and EBD procedures is recommended unless contraindicated.

N95 or class 2 filtering face-piece (FFP2) respirators are recommended when performing aerosol-generating procedures and to use medical masks when providing care to 
Table 2 Recommendation of administrative measures for staff

General management

- Traveling outside the country should be prohibited.

- Staff who have recent travel history must undergo a 14-day self-quarantine.

- Temperature checks must be done and recorded twice daily.

- Dividing the staff into two working groups with different work shifts (skeletal workforce).

- Face masks must be worn during all patient contact points.

- Frequent hand-cleaning with an ABHR* or soap and water.

Intraoperative measures

- Machine surfaces and dermatology beds must be covered with a plastic wrap.

- The following PPE must be worn at all times:

- Gloves to protect the hands (and properly discarded after each patient contact),

- Long gowns/aprons to protect skin and/or clothing,

- N95 or FFR2 to protect the mouth and nasal orifices,

- Goggles for eye protection,

- Face shields,

- Smoke evacuators must be used to capture the plumes when doing laser and EBD procedures,

- Covering the mouth and nose of a patient with a facemask during laser and EBD.

Postoperative measures

- All contaminated PPE must be properly removed, cleaned, or disposed. - Hand hygiene must be performed after the removal of gloves.

*ABHR, alcohol-based handrub; $P P E$, personal protective equipment; $F F R 2$, class 2 filtering face-piece respirators

suspected or confirmed cases [7,8]. To avoid iatrogenic spread of viral particles from a used facemask, it is important to follow the recommendation of the USCDC on how to properly put on and take off a disposable respirator. To reiterate, wearing a protective mask will not protect HCWs against COVID-19 if it is not accompanied by meticulous hand hygiene, eye protection, gloves, and a gown. Long-sleeved water-resistant gowns or a single-use plastic apron worn over a non-water-resistant gown must be used at all times (Table 2).

\section{Engineering measures: Environment care of clinic}

Machine surfaces and dermatology beds must be covered with a plastic wrap for ease of cleaning and disinfection. The procedure room must be kept physically clean and air-dried to reduce the viability of SARS-CoV-2. At room temperature, the virus remains viable from $2 \mathrm{~h}$ up to 9 days [9]. Ultraviolet (UV)-C irradiation has been widely used because of its germicidal effects by inhibiting cellular replication [10]. Due to this characteristic, its use in inactivating coronaviruses was initially explored during the severe acute respiratory syndrome (SARS) outbreak back in 2003 [11]. While there is a potential in using UV-C lamps for sterilization during this pandemic, no studies have been published to date on its ability to destroy the novel coronavirus.

\section{Engineering measures: Exhaust ventilation procedures}

Surgical smoke is produced by thermal destruction of target tissue and consists of $95 \%$ vapor and 5\% particulate matter (infectious and non-infectious). It has been found that viral diseases such as genital warts caused by the human papillomavirus (HPV) can be transmitted via carbon dioxide $\left(\mathrm{CO}_{2}\right)$ laser-generated plumes to produce nasopharyngeal lesions. Smoke evacuators are recommended for ablative laser procedures and electrosurgery. Importantly, the nozzle of the smoke evacuator hose must be kept less than an inch away from the source of emission to ensure efficient plume evacuation [12].

\section{Conclusions}

The practice of dermatology carries an equal risk of exposure to SARS-CoV-2 to both patients and HCWs. We are facing many unknowns, and thus, careful monitoring and further studies must be continued. At the peak of this pandemic, it must be emphasized that all non-emergent cases be rescheduled or deferred to teledermatology consults. If absolutely necessary, dermatologists are urged to abide by the consensus guidelines set forth by the WHO and of local dermatological societies to minimize potential risks of transmission.

\section{Compliance with ethical standards}

Conflict of interest The authors declare that they have no conflict of interest.

Ethical approval Not applicable (This manuscript is not an experimental study).

\section{References}

1. Guan WJ, Ni ZY, Hu Y, Liang WH, Ou CQ, He JX et al (2020) Clinical characteristics of coronavirus disease 2019 in China. N Engl J Med 382(18):1708-1720. https://doi.org/10.1056/ NEJMoa2002032

2. Li R, Pei S, Chen B, Song Y, Zhang T, Yang W et al (2020) Substantial undocumented infection facilitates the rapid dissemination of novel coronavirus (SARS-CoV-2). Science. 368(6490): 489-493. https://doi.org/10.1126/science.abb3221

3. Chang L, Yan Y, Wang L (2020) Coronavirus disease 2019: coronaviruses and blood safety. Transfus Med Rev 34(2):75-80. https://doi.org/10.1016/j.tmrv.2020.02.003

4. Kwatra SG, Sweren RJ, Grossberg AL (2020) Dermatology practices as vectors for COVID-19 transmission: a call for immediate cessation of nonemergent dermatology visits. J Am Acad Dermatol 82(5):e179-ee80. https://doi.org/10.1016/j.jaad.2020.03.037

5. Huang C, Wang Y, Li X, Ren L, Zhao J, Hu Y, Zhang L, Fan G, Xu J, Gu X, Cheng Z, Yu T, Xia J, Wei Y, Wu W, Xie X, Yin W, Li H, Liu M, Xiao Y, Gao H, Guo L, Xie J, Wang G, Jiang R, Gao Z, Jin 
Q, Wang J, Cao B (2020) Clinical features of patients infected with 2019 novel coronavirus in Wuhan, China. Lancet 395(10223):497506

6. World Health Organization (2020) Rational use of personal protective equipment (PPE) for coronavirus disease (COVID-19): interim guidance, 19 March 2020. World Health Organization

7. Adhikari SP, Meng S, Wu YJ, Mao YP, Ye RX, Wang QZ, Sun C, Sylvia S, Rozelle S, Raat H, Zhou H (2020) Epidemiology, causes, clinical manifestation and diagnosis, prevention and control of coronavirus disease (COVID-19) during the early outbreak period: a scoping review. Infect Dis Poverty 9(1):29

8. Derrick JL, Li PT, Tang SP, Gomersall CD (2006) Protecting staff against airborne viral particles: in vivo efficiency of laser masks. J Hosp Infect 64(3):278-281

9. Wax RS, Christian MD (2020) Practical recommendations for critical care and anesthesiology teams caring for novel coronavirus
(2019-nCoV) patients. Can J Anaesth 67(5):568-576. https://doi. org/10.1007/s12630-020-01591-x

10. Casini B, Tuvo B, Cristina ML, Spagnolo AM, Totaro M, Baggiani A et al (2019) Evaluation of an ultraviolet C (UVC) light-emitting device for disinfection of high touch surfaces in hospital critical areas. Int J Environ Res Public Health 16(19):3572. https://doi. org/10.3390/ijerph16193572

11. Darnell ME, Subbarao K, Feinstone SM, Taylor DR (2004) Inactivation of the coronavirus that induces severe acute respiratory syndrome. SARS-CoV J Virol Methods 121(1):85-91. https://doi. org/10.1016/j.jviromet.2004.06.006

12. Katoch S, Mysore V (2019) Surgical smoke in dermatology: its hazards and management. J Cutan Aesthet Surg 12(1):1-7

Publisher's note Springer Nature remains neutral with regard to jurisdictional claims in published maps and institutional affiliations. 